\title{
Universidade e comunidade sob a ótica do curso Educação do Campo
}

\author{
na Unipampa
}

\author{
University and community under the optics of the Rural Education course in Unipampa
}

\author{
Algacir José Rigon* \\ Vinícius Piccin Dalbianco ${ }^{* *}$
}

\section{Resumo}

Ao conceber a universidade como parte integrante e fundamental da estrutura social, pretende-se, por meio das experiências do curso de licenciatura Educação do Campo da Universidade Federal do Pampa (Unipampa), descrever e discutir a relação entre a universidade e a comunidade. Para cumprir com essa finalidade, foi realizada uma revisão de literatura sobre os temas trazidos, bem como foi analisado o Plano de Desenvolvimento Institucional da Unipampa e o Projeto Pedagógico do Curso Educação do Campo, frente aos desafios da formação docente numa proposta não convencional de formação universitária. O Manifesto de Córdoba em 1918 pontuava questões importantes para o protagonismo dos estudantes, bem como para o rompimento com o modelo focado no ensino e na pesquisa, reformando a universidade na direção da abertura para a comunidade e da reestruturação da gestão, com o objetivo de viabilizar maior participação dos estudantes. Com o desafio de formação de um novo educador e de um novo gestor, com foco na formação para a docência, para a gestão, para a política e para a pesquisa, o curso em pauta atende os princípios do manifesto na sua organização curricular e na viabilização da participação dos estudantes e, especialmente, da comunidade nas instâncias decisórias. A organização curricular em alternância e interdisciplinar, a constituição do conselho comunitário, bem como a postura de escuta dos estudantes nos diferentes espaços retroalimentam a relação entre universidade e comunidade, de modo a resultar em uma formação crítica e emancipatória com perspectiva de mudanças do sistema social vigente.

Palavras-chave: Compromisso social. Comunidade. Educação do campo. Formação de professores. Sujeitos.

\section{Abstract}

In designing the university as an integral and fundamental part of the social structure, it is intended, through the experiences of the Rural Education Course - Licentiate of the Federal University of Pampa (UNIPAMPA), to describe and discuss the relationship between the university and the community. In order to fulfill this purpose, a literature review was carried out on the themes brought in, as well as, the UNIPAMPA Institutional Development Plan (PDI) and the Rural Education Course (PPC) Pedagogical Project were analyzed in face of the training challenges an unconventional proposal for university education. The Manifesto of Cordoba in 1918 pointed to important issues for the protagonism of students, as well as for the university to break with its model focused on teaching and research, reforming in the direction of its openness to the community and in the restructuring of

Recebido em 31/03/2018 - Aprovado em 25/06/2018

http://dx.doi.org/10.5335/rep.v25i3.8571

Doutor em Educação pela Universidade de São Paulo. Professor adjunto da Universidade Federal do Pampa, campus Dom Pedrito. E-mail: ajrigon@gmail.com

** Doutor em Extensão Rural pela Universidade Federal de Santa Maria. Professor adjunto da Universidade Federal do Pampa, campus Itaqui. E-mail: vinidalbianco@yahoo.com.br 


\begin{abstract}
management, with the aim of enabling greater student participation. With the challenge of training a "new" educator and manager, focusing on training for teaching, for management, for politics and for research, the course in question falls within this perspective, providing for the fulfillment of these principles of the Manifesto, in its curricular organization and in the feasibility of the participation of the students, and especially of the community in the decision-making bodies. The alternating and interdisciplinary curricular organization, the constitution of the Community Council, as well as the listening posture of the students in the different spaces, feeds back the University - Community relationship in order to have, as a result, a critical and emancipatory formation with a perspective of changes in the current social system.
\end{abstract}

Keywords: Community. Rural education. commitment. Subjects. Teacher training.

As universidades foram até aqui o refúgio secular dos medíocres, a renda dos ignorantes, a hospitalização segura dos inválidos e - o que é ainda pior - o lugar onde todas as formas de tiranizar e de insensibilizar acharam a cátedra que as ditasse [...]. A juventude já não pede. Exige que se reconheça o direito de exteriorizar esse pensamento próprio nos corpos universitários por meio de seus representantes. Está cansada de suportar os tiranos. Se foi capaz de realizar uma revolução nas consciências, não pode desconhecer-se a capacidade de intervir no governo de sua própria casa (MANIFESTO..., 1918, p. 1).

\title{
Introdução
}

Entre as funções da universidade de longa data, especialmente desde o século XIX, destaca-se o modelo voltado para o ensino e para a pesquisa, produção de conhecimentos para alguma aplicabilidade em setores da sociedade. Contudo, esse modelo tende a ser superado na direção de melhorias na relação entre a universidade e a sociedade, no sentido de que o Estado possa contribuir com o conjunto de políticas sociais que tragam benefícios amplos, seja como contraponto aos problemas nefastos do capitalismo, seja no sentido da aproximação da universidade com os diferentes setores da sociedade, relevantes para o desenvolvimento socioeconômico de uma localidade. Na América Latina, o passo dado em direção ao movimento pela reforma universitária teve o protagonismo dos estudantes de Córdoba, em 1918, registrado, inclusive, no Congresso Internacional de Estudantes do México, em 1921, com duas reivindicações básicas: "1) a intervenção dos estudantes na administração da universidade e 2) o funcionamento das cátedras livres e de cátedras oficiais, com iguais direitos, a cargo de professores com reconhecida capacidade nas matérias" (MARIÁTEGUI, 1981, p. 129, tradução nossa).

O curso de licenciatura Educação do Campo, nesse contexto, atende a uma demanda de formação e qualificação de profissionais para atuar na educação do campo, contribuindo para formação, qualificação e atualização na área das ciências da natureza dos anos finais dos ensinos fundamental e médio vinculados ao meio rural. Na Universidade Federal do Pampa (Unipampa), o curso é ofertado no campus localizado no município de Dom Pedrito e atende a demanda de municípios 
vizinhos, como Rosário do Sul, Alegrete, Santana do Livramento, Candiota, Hulha Negra, Lavras do Sul e Canguçu, além de povos indígenas localizados no município de Tenente Portela.

A educação do campo como política pública nasceu das demandas dos movimentos sociais camponeses na construção de uma política educacional para os assentamentos de reforma agrária. Esse é um fato relevante na compreensão da história da educação do campo, pois se trata de um movimento da sociedade que adentra as universidades. Enquanto uma conquista, é resultado da organização desses povos camponeses. Esse processo é demonstração da efetiva articulação entre a universidade e os movimentos sociais, especificamente os camponeses, uma vez que:

1) o problema educacional não é senão uma das faces do problema social, por isso não pode ser solucionado isoladamente; 2 ) a cultura de toda sociedade é a expressão ideológica dos interesses da classe dominante. A cultura da sociedade atual é, portanto, a expressão ideológica dos interesses da classe capitalista; 3) a última guerra imperialista (1914-1918), rompendo o equilíbrio da economia-burguesa, colocou em crise sua própria cultura; 4) esta crise só pode ser superada com o advento de uma cultura socialista (MARIÁTEGUI, 1981, p. 150-151, tradução nossa).

Para dar conta dessa problemática e atender à demanda social, este curso prioriza a formação de profissionais da educação básica capazes de atender às especificidades que caracterizam as áreas rurais, bem como as áreas consideradas perurbanas ou rurbanas, não densamente povoadas, localizadas a caminho da zona rural, espaços com características e identidade rurais nos quais os sujeitos produzem suas condições materiais de existência a partir do trabalho na e com a terra. Ainda, é possível considerar municípios, a exemplo de Dom Pedrito, como tipicamente rurais, pois suas atividades urbanas, mesmo no espaço urbano, têm vínculo direto com o campo. É o que se entende por nova ruralidade brasileira. Coincidência aparente, as atividades da universidade, em específico, da extensão, lembram as facetas da tradição europeia: "educação continuada e educação voltada para as classes populares; extensão voltada para a prestação de serviços na área rural" (NOGUEIRA, 2005, p. 16-17). Enfim, como o curso de licenciatura Educação do Campo representa a relação universidade e comunidade, realizando um objetivo de vanguarda na medida em que potencializa essa relação e torna protagonistas os sujeitos das comunidades camponesas? Quais são os desafios da universidade nessa nova proposta formativa? Em especial, quais são os desafios na atuação docente nesse curso?

Para a execução deste trabalho, foi realizado um estudo bibliográfico sobre as mudanças na formação universitária, principalmente aquelas provocadas a partir do Manifesto de Córdoba, correlacionando as propostas deste manifesto com as 
abordagens sobre educação que propõem uma formação universitária aberta para compreender a realidade dos estudantes e, consequentemente, da comunidade. $\mathrm{O}$ caso estudado foi o do curso de licenciatura Educação do Campo da Unipampa. Para isso, foi utilizado como base o Plano de Desenvolvimento Institucional (PDI) da Unipampa e o Projeto Pedagógico do Curso (PPC). A partir da revisão do PPC, buscou-se analisar os eixos de formação possibilitados pelo curso, a relação entre o ensino, a pesquisa e a extensão e os desafios da formação docente frente a uma proposta não convencional de formação universitária.

\section{0 curso de licenciatura Educação do Campo na Unipampa}

A aprovação do curso de licenciatura Educação do Campo na Unipampa ocorreu via edital (Secadi/Sesu/MEC) em dezembro de 2012, e as aulas da primeira turma aconteceram no mês de julho de 2014. Desde a sua criação, o curso é comprometido com concretizar a missão institucional da Unipampa, tendo como principal objetivo a formação de educadores(as) para a atuação na Educação do Campo. A atuação dos futuros docentes, capazes de realizar gestão de processos educativos e gestão de instituições de educação básica, visa aos anos finais dos ensinos fundamental e médio na área das ciências da natureza. Essa formação objetiva o desenvolvimento de estratégias de ensino-aprendizagem que busquem a formação de sujeitos autônomos e criativos, bem como a investigação de questões inerentes à sua realidade e à sustentabilidade da vida no campo, estimulando a formação continuada tanto pela reflexão sobre a própria prática como pela continuidade de estudos em programas de pós-graduação.

Esta perspectiva de formação está ancorada numa concepção teórica que apresenta três fundamentos: a) prevalência de referências histórico-críticas em oposição a teorias positivistas-funcionalistas; b) análise do processo histórico como elemento fundamental para a compreensão do contexto atual e para a construção da crítica aos desenvolvimentos social, econômico e político com foco para a realidade da região da Campanha Gaúcha; c) valorização da cultura, do capital social, dos laços sociais e crítica ao processo de desenvolvimento neoliberal, ao estado mínimo e ao desenvolvimento com base nos pressupostos econômicos. Esta abordagem é destacada como pressuposto metodológico do curso:

Este caráter complexo do desafio da formação humana em Educação do Campo fundamenta-se, por sua vez, na concepção de que o campo é território de produção de vida, de produção de novas relações sociais, de novas relações entre os homens e a natureza, de novas relações entre o rural e o urbano. A partir daí, faz-se necessária uma concepção filosófica e teórica que permita articular o pensar e o fazer pedagógico com a construção de alternativas de desenvolvimento sustentável das comunidades do campo (UNIVERSIDADE FEDERAL DO PAMPA, 2016, p. 31). 
Conforme o PPC (UNIVERSIDADE FEDERAL DO PAMPA, 2016), com o curso Educação do Campo, busca-se atender uma demanda reprimida de formação de professores, principalmente quando se pensa na especificidade do campo e na formação para atuar no ensino de ciências nos anos finais dos ensinos fundamental e médio.

Além da legislação específica para a Educação do Campo, o curso também atende às normativas gerais para os cursos de licenciatura, às regulamentações específicas da Unipampa e às normas gerais do âmbito da educação. Com este propósito, o curso se apresenta na seguinte forma:

Nome: Educação do Campo

Campus: Dom Pedrito

Grau: licenciatura

Área: ciências da natureza

Atuação: anos finais dos ensinos fundamental e médio (Biologia, Física e Química)

Turno: integral

Número de vagas: 60 vagas anuais, sendo 30 ofertas por semestre.

Integralização: 8 semestres / 4 anos

Tempo mínimo de integralização: 6 semestres / 3 anos

Tempo máximo de integralização: 12 semestres / 6 anos

Carga horária total: 3.290 horas

Site: <http://cursos.unipampa.edu.br/cursos/lecampo-dp/>

O curso é dividido em semestre de verão e semestre de inverno, organizado pelo regime de alternância. Em cada semestre, ocorre o Tempo Universidade (TU) e o Tempo Comunidade (TC). No semestre de verão, o TU ocorre nos meses de janeiro e fevereiro, e o TC, nos meses de março, abril, maio e junho. No semestre de inverno, o TU ocorre nos meses de julho e agosto, e o TC, nos meses de agosto, setembro, outubro e novembro. No TU, o curso funciona em período integral. No TC, os estudantes cumprem a carga horária prevista de acordo com a dinâmica da comunidade de origem ou de inserção e conforme o cronograma das atividades previstas em cada semestre.

A Pedagogia da Alternância, de origem francesa (1935), ligada ao Padre Granereau, chegou ao Brasil em 1969, com a constituição da Escola da Família Agrícola (EFA), sendo projetada como uma alternativa para o ensino no meio rural em crise (NOSELLA, 2012). O que motivava Granereau era sua percepção em relação ao desinteresse do Estado e da Igreja pelas problemáticas do homem do campo, especialmente no que concernia à educação, que culminava com o isolamento do 
camponês. Nesse contexto, organizou um grupo de jovens para cursos, uma semana por mês, com conteúdos ligados à vida produtiva agrícola. A partir de então, a Pedagogia da Alternância torna-se um conceito polissêmico, que carrega vários significados e também permite um uso diverso, a depender da região ou da base teórica que o fundamenta. Contudo, visualiza-se um elemento em comum: o trabalho produtivo como princípio educativo; a atividade de produção da vida é o centro no qual se articula o ensino formal. Nesse sentido, a Pedagogia da Alternância parte da unidade de articulação entre a teoria e a prática, alternando tempos e espaços entre a escola, ou a universidade, e a comunidade, a propriedade, o assentamento, o movimento social, enfim, entre o espaço formativo propriamente dito e o espaço de trabalho de vínculo do estudante. Os tempos também se alternam, considerando, entre outros aspectos, as peculiaridades da produção da vida desses sujeitos, características dos seus locais de vida, por exemplo, o tempo de colheita, o melhor período para disposição de tempo para os deslocamentos.

A expressão "regime de alternância”, utilizada no PPC, é um desdobramento dessa concepção, que preserva, especialmente, a alternância do tempo e do espaço formativo. O currículo, o plano pedagógico, a metodologia e a avaliação, embora no horizonte de expectativas, são as dimensões da Pedagogia da Alternância que não estão incorporadas em sua totalidade.

Para dar conta deste desafio educativo, é demandado um "novo" educador, que seja capaz de compreender o processo educativo em sua dimensão ampla e complexa e de articular as suas diversas dimensões. Por isso, a proposição curricular do curso Educação do Campo é a transversalidade do conhecimento proposta por eixos articuladores (e suas dimensões formativas) e eixos orientadores que direcionam os componentes curriculares em cada semestre letivo, conforme pode ser observado no Quadro 1.

A proposta metodológica do curso se baseia em eixos que objetivam garantir a transversalidade e a interdisciplinaridade da formação. Dessa forma, o eixo orientador Educação do Campo visa a responder o desafio da complexidade do seu próprio objeto de estudo, ou seja, a necessidade de encontrar indicativos conceituais e metodológicos para oferecer formação docente contextualizada e consistente, tornando-se um sujeito capaz de propor e implementar as transformações político-pedagógicas necessárias à rede de escolas que atendem a população que trabalha e vive no e do campo (UNIVERSIDADE FEDERAL DO PAMPA, 2016, p. 55). 
Quadro 1 - Representação esquemática dos eixos orientador, articuladores e temáticos

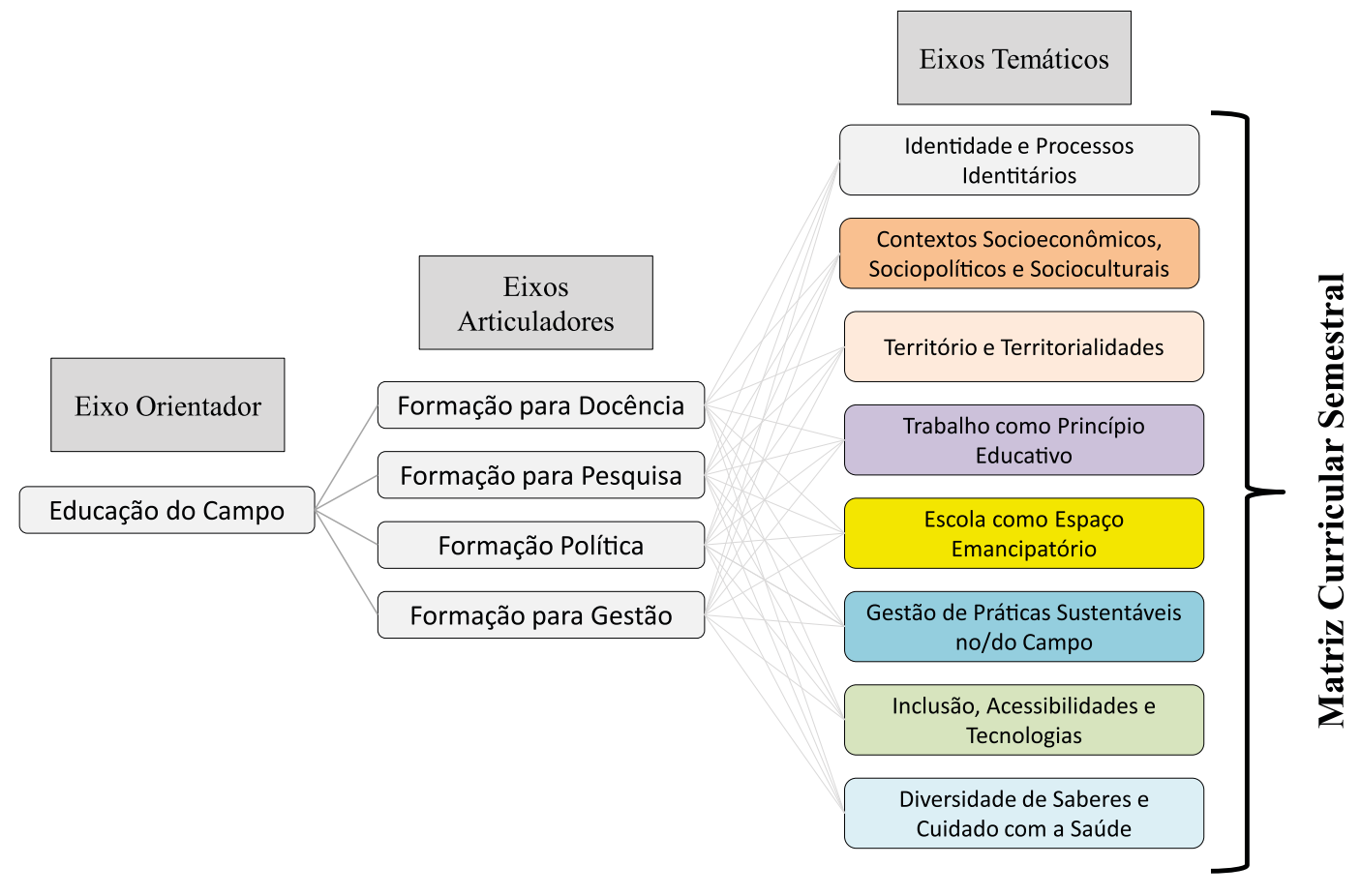

Fonte: elaboração dos autores.

O eixo de Formação para Docência orienta a formação estudantil para a criação das condições teóricas e metodológicas necessárias à concretização de articulações com os diferentes conhecimentos das áreas específicas do curso. É o eixo que pretende garantir o processo interdisciplinar entre conteúdos e componentes curriculares.

O eixo Formação para Pesquisa tem como propósito contribuir para a formação de um professor pesquisador e reflexivo, criando a possibilidade de que o curso, além de contribuir diretamente para a construção de uma escola que possa responder à demanda imediata da escolarização do campo, construa espaços de pesquisa, intervenção e produção de experiências inovadoras. O curso baseia-se na investigação como uma possibilidade de reflexão sobre os fenômenos estudados nas áreas das ciências da natureza, de modo que os acontecimentos da vida dos estudantes e da educação do campo se tornem objetos de pesquisa e reflexão.

O eixo de Formação Política destaca a importância de os estudantes conhecerem as políticas de educação e compreenderem suas implicações organizacionais e pedagógicas. Implica, para a formação docente, a investigação e o estudo das transformações históricas e conjunturais da sociedade, de modo a desvendar as 
configurações que estruturam as organizações da sociedade, incluindo a arquitetura escolar responsável pela formação do indivíduo e dos conhecimentos inerentes às transformações da sociedade. Há de se destacar a importância desse eixo que, desde a sua concepção, tem em vista o incentivo a organização estudantil, para que os estudantes sejam protagonistas de sua história, participando ativamente da vida universitária, inclusive na forma da representação discente nas várias comissões do curso ou da instituição.

O eixo Formação para a Gestão surge da necessidade de profissionais qualificados que deem conta da cultura do campo, das mudanças da legislação sobre Educação do Campo e de aspectos constitutivos das singularidades do meio rural brasileiro. Esse eixo colabora para compreensão e vivência de conceitos como autonomia, democracia, liberdade de expressão e opinião, decisões coletivas e compartilhadas. A gestão envolve as instâncias da escola e dos espaços não formais de educação. A gestão de processos educativos escolares compreende a discussão e a construção do projeto político-pedagógico, do regimento escolar e do conselho de classe e a organização do trabalho escolar nas escolas do campo. O processo de gestão não formal discute questões relacionadas a associativismo, cooperativismo, sustentabilidade, agroecologia, baseados nas relações de colaboração e de bem comum de uma comunidade, bem como o apoio a iniciativas e projetos de desenvolvimento comunitário sustentável para as escolas e para as famílias que vivem no e do campo.

De acordo com o perfil profissional pretendido para os(as) docentes do curso de licenciatura Educação do Campo, há possibilidade de atuação em diversas áreas, contribuindo para o aperfeiçoamento da qualidade de vida da comunidade na qual estiver inserido(a) o(a) egresso(a). Espera-se dele(a) compromisso com a escola pública de qualidade, enquanto elemento socializador dos conhecimentos historicamente produzidos pela humanidade, articulando-os com os conhecimentos da cultura do campo. Também deve atuar nos processos educativos, especificamente no trabalho formativo, organizando, coletivamente com as famílias e/ou com grupos sociais de origem, a implantação de iniciativas e/ou projetos de desenvolvimento comunitário sustentável, que incluam a participação da escola (UNIVERSIDADE FEDERAL DO PAMPA, 2016, p. 55).

$\mathrm{O}(\mathrm{A})$ egresso(a) da Unipampa deve assumir sua responsabilidade com a universidade pública e a sociedade, trabalhando com comprometimento, responsabilidade social e cidadania. Nesse cenário, espera-se uma postura e uma prática diferenciadas desse(a) estudante, de acordo como a perspectiva de Freire 
Conhecer, na dimensão humana, que aqui nos interessa, qualquer que seja o nível em que se dê, não é o ato através do qual um sujeito, transformado em objeto, recebe, dócil e passivamente, os conteúdos que outro lhe dá ou impõe [...]. O conhecimento, pelo contrário, exige uma presença curiosa do sujeito em face do mundo. Requer uma ação transformadora sobre a realidade. Demonstra uma busca constante. Implica em invenção e em reinvenção. Reclama a reflexão crítica de cada um sobre o ato mesmo de conhecer, pelo qual se reconhece conhecendo e, ao reconhecer-se assim, percebe o "como" de seu conhecer e os condicionamentos a qual está submetido seu ato [...]. Conhecer é tarefa de sujeitos, não de objetos. E é como sujeito, e somente enquanto sujeito, que o homem pode realmente conhecer (2010, p. 27).

No ato formativo, o público prioritário do curso são pessoas que concluíram o ensino médio, professores em exercício nas escolas do campo, profissionais da educação em escolas públicas do campo, profissionais com experiências educacionais alternativas de educação do campo, vinculados a movimentos sociais ou sindicais do campo e educadores de comunidades do campo (quilombolas, indígenas, pescadores artesanais, agricultores, etc.).

\section{Articulação ensino-pesquisa-extensão}

Atividades de ensino, pesquisa e extensão são estruturantes na promoção de formação superior para constituir sujeitos comprometidos a atuar com vistas aos desenvolvimentos regional, nacional e internacional. A vivência nas atividades de origem (trabalho - realidade), por meio da alternância de tempos e espaços formativos, permite que os sujeitos, docente e discente, e a comunidade interajam mediados por um conteúdo socialmente referenciado que, ao mesmo tempo, serve como balizador das atividades indissociáveis de ensino, pesquisa e extensão.

$\mathrm{O}$ ensino se distingue das demais atividades por carregar uma intencionalidade que amplia a responsabilidade de preparação do educador, uma vez que pode ser tomada como materialização de objetivos e conteúdos resultantes da vivência em determinada realidade. A visão de ensino congrega uma concepção histórico-cultural que não se limita ao espaço físico da sala de aula, está nos demais espaços que expressam um conteúdo multi, inter e transdiciplinar como resultante das práticas sociais

A pesquisa e a produção de conhecimento sistematizado, no curso, acontecem mediadas pelo lugar que se ocupa na sociedade e na atividade social, constituindo-se como mecanismo de solução dos problemas do cotidiano do espaço rural, sejam eles socioeconômicos, ambientais ou culturais, que afligem a humanidade enquanto uma totalidade. O objetivo da pesquisa é criar e recriar conhecimentos que visem às transformações sociais necessárias e determinar que a questão central do que será pesquisado e os fins e interesses tenham como norte os pressupostos do 
curso Educação do Campo e as necessidades das comunidades de origem dos estudantes. A metodologia a ser usada na pesquisa pretende propiciar a participação das populações na condição de sujeitos (não apenas de espectadores), a partir do uso de metodologias participativas, dialógicas, a fim de proporcionar a abertura de um leque diversificado, que balize o trabalho conjunto entre universidade e setores da sociedade.

O indivíduo não é somente resultado da sociedade, mas também tem um papel de ação nela a ser concretizado na universidade enquanto extensão, enquanto prática socioeducativa de imersão na comunidade, contribuindo com soluções para os problemas levantados e alimentando e qualificando com experiências o debate educativo. Desse modo, a extensão universitária, expressa no curso Educação do Campo a partir do TC, proporciona a articulação entre o ensino e a pesquisa. $\mathrm{Ou}$ seja, o regime de alternância tem como pressuposto a interconexão entre universidade e comunidade, proporcionando o afloramento da pesquisa e da extensão como processo, não como objetivo fim. É a inversão da lógica tradicional do ensino, em que o olhar para fora da universidade é baseado na intencionalidade da reprodução acadêmica.

A atividade de extensão teve seu reconhecimento legal, inclusive, a partir do fim da década de 1980, culminando com o Fórum de Pró-Reitores de Extensão e a constituição da Rede Nacional de Extensão (Renex), que definiram o conceito de extensão no I Encontro Nacional de Pró-Reitores de Extensão:

A Extensão Universitária é o processo educativo, cultural e científico que articula o Ensino e a Pesquisa de forma indissociável e viabiliza a relação transformadora entre universidade e sociedade. A Extensão é uma via de mão dupla, com trânsito assegurado à comunidade acadêmica, que encontrará, na sociedade, a oportunidade de elaboração da práxis de um conhecimento académico. No retorno à Universidade, docentes e discentes trarão um aprendizado que, submetido à reflexão teórica, será acrescido àquele conhecimento. Esse fluxo, que estabelece a troca de saberes sistematizados, acadêmico e popular, terá como consequência: a produção do conhecimento resultante do confronto com a realidade brasileira e regional; a democratização do conhecimento académico e a participação efetiva da comunidade na atuação da Universidade. Além de instrumentalizadora desse processo dialético de teoria/prática, a Extensão é um trabalho interdisciplinar que favorece a visão integrada do social (FÓRUM DE PRÓ-REITORES DE EXTENSÃO DAS UNIVERSIDADES PÚBLICAS BRASILEIRAS, 2001, p. 4).

As vivências do campo, as atividades rurais são os instrumentos básicos da articulação dos processos de ensino, pesquisa e extensão no curso Educação do Campo - voltado para uma agricultura de base ecológica e sustentável em suas diferentes dimensões, ambiental, econômica, social e cultural, entre outras - e na Unipampa, cujo papel das políticas de extensão (UNIVERSIDADE FEDERAL DO PAMPA, 2013) é promover o imbricamento entre universidade e sociedade, de 
modo a promover ação coletiva entre ambas. Outros princípios, inclusive pautados na perspectiva da extensão universitária no Brasil, estão afinados com essa visão do curso, isto é, buscam qualificar os compromissos sociais e ético-políticos da universidade na forma de uma relação dialógica com a sociedade, tendo a inter e a transdisciplinariedades como organizadores dessas ações. Conta-se, ainda, com um movimento interno, para dentro da universidade, no sentido de impor aos setores pedagógicos e administrativos o desenvolvimento de atividades que qualifiquem a cultura científica com a cultura das humanidades, papel fundamental das bibliotecas, atividades nos laboratórios, galerias e exposições, entre outros; enfim, a justa mediação entre os produtores do conhecimento e os beneficiários dele.

\section{Desafios da atuação docente}

A proposta de formação construída pelo curso Educação do Campo desafia a atuação docente. Conforme é destacado pelo PPC, a abordagem e a estratégia metodológicas

exigem uma ação pedagógica inovadora, centrada na realidade: do educando, do contexto social, econômico, educacional e político da região onde a Universidade está inserida. Pressupõe, ainda, uma concepção de educação que reconheça o protagonismo de todos os envolvidos no processo educativo e que tenha a interação como pressuposto epistemológico da construção do conhecimento (UNIVERSIDADE FEDERAL DO PAMPA, 2016, p. 18, grifo nosso).

A ação educativa proposta pressupõe "a construção do conhecimento como resultado interativo da mobilização de diferentes saberes, que não se esgotam nos espaços e tempos delimitados pela sala de aula convencional" (UNIVERSIDADE FEDERAL DO PAMPA, 2013, p. 26, grifo nosso). Para isso, o estudante é sujeito do processo educativo, sendo necessário o reconhecimento da sua realidade, de modo a se valer de diferentes estilos de aprendizagem, individuais e coletivos. Nesse horizonte, a educação democrática se viabiliza pela participação popular, pela participação não só do estudante enquanto sujeito, mas também de sua respectiva comunidade ou organização social, que é o meio de intervir nas tomadas de decisões políticas implicadas no coletivo, especialmente se considerado que "[...] a participação popular só será política e democrática se puder produzir as próprias leis, normas, regras e instituições que dirijam a vida sociopolítica" (CHAUÍ, 2006, p. 140).

Para este desafio educativo, é demandado, num primeiro momento, um "novo" educador. A transversalidade do conhecimento proposta pelos eixos articuladores e norteadores e a abordagem histórica e crítica do referencial pedagógico proposto 
exigem um professor que consiga atuar além das disciplinas, de modo a articular outros campos do conhecimento, no caso específico, aqueles que versam sobre as transformações do campo, da natureza, das pessoas que vivem no campo, da escola do campo. Esse desafio se configura tanto para o desenvolvimento dos conteúdos em sala de aula quanto para a articulação desses conteúdos com a realidade do campo e da educação do campo. Ou seja, a atuação educativa não se restringe à articulação do conhecimento entre a teoria e a prática como ação pedagógica em sala de aula, mas se alarga à vivência da prática como objeto de questionamento e reflexão da teoria.

Apoiado em um papel empenhado no desenvolvimento rural agroecológico, entre os principais desafios contemporâneos do curso Educação do Campo, destaca-se a necessidade de ampliação da relação dos docentes e estudantes com a realidade do território das escolas do campo. Mas essa demanda não está restrita ao campo do aprimoramento das relações sociais. Amplia-se para o campo da formação do conhecimento científico, a partir da combinação entre o saber teórico e o saber empírico/prático das ciências da natureza. O campo do desenvolvimento rural agroecológico deve contribuir para a aproximação entre o saber popular e o saber científico. Com isso, "os cursos de formação de professores devem garantir uma sólida cultura que lhes permita atingir uma aguda consciência da realidade em que vão atuar associada a um consistente preparo teórico-científico que os capacite à realização de uma prática pedagógica coerente e eficaz" (SAVIANI, 2010, p. 209).

$\mathrm{O}$ modo como os agricultores familiares e camponeses manejam os elementos da natureza carrega consigo um universo de combinações científicas, podendo ser caracterizado como um caso concreto de transdisciplinaridade, em que o elemento norteador não está no conteúdo disciplinar, mas no efeito do trabalho sobre as convenções naturais. Nessa perspectiva, ocorrem inúmeros processos que buscam o aproveitamento dos recursos locais e naturais no desenvolvimento das práticas agrícolas, requerendo menos capital e utilização mais intensiva e eficiente da mão de obra. Compreende-se que esse aprendizado prático coletivo é objeto de análise do curso Educação do Campo, tendo em vista que se quer formar educadores que vão atuar na formação educacional de agricultores familiares e camponeses.

Isso significa, portanto, que os cursos de preparação de professores devem visar à formação de seres humanos plenamente cultos, profundos conhecedores da história concreta dos homens, em lugar da formação de indivíduos "curtos", preconizada pela atual política de formação de professores que vem incentivando os cursos de curta duração dos institutos superiores de educação e suas escolas normais superiores (SAVIANI, 2004, p. 48 apud DUARTE, 2004, p. 49). 
A formação teórico-científica deve colocar os educadores em condições de refletir e de se interrogar sobre questões vitais para o exercício crítico da atividade docente. $\mathrm{O}$ educador deve se perguntar sobre: o que consiste a sua atividade; qual é o sentido dela; o que pensa da sociedade em que vive; o que sabe sobre a sua profissão; como a vê e como se vê na docência; o que ensina, como ensina e com que fins; o que precisa saber para realizar com coerência e eficácia a sua prática pedagógica; tem domínio satisfatório dos conhecimentos de sua área de atuação e dos conhecimentos didático-pedagógicos; como aprende a ser professor; como age e reage nas situações de ensino; como entende a sua relação com seus pares e com a escola na qual trabalha; como entende e o que projeta na relação com a comunidade e o meio camponês; como vê a si e o estudante; como entende a sua relação com este e com o conhecimento; o que a forma como o estudante aprende demanda para seu trabalho e formação. A formação dos futuros professores, nessa direção, necessita prever três itens fundamentais:

a) uma boa formação inicial provida nas universidades em cursos de longa duração; b) condições adequadas de trabalho que lhes permitam atualização constante, preparação consistente de suas atividades curriculares e atendimento às necessidades pedagógicas dos estudantes, revendo e reelaborando os conteúdos e os métodos do ensino ministrado; c) participação na organização sindical dos docentes de modo que potencializem as lutas coletivas em torno dos aspectos envolvidos nos itens anteriores (SAVIANI, 2010, p. 34).

Cabe lembrar que não se trata de culpar professores pelo fracasso escolar, mas de apontar que eles também são vítimas da situação social vigente (sistema capitalista), em que se atrelam os interesses dominantes à formação (deformação) de professores. No sistema capitalista, é de interesse da classe dominante que não se transmita o saber escolar às classes dominadas, por isso o saber (conteúdo) e o método (metodologias amiúde sem competências) transmitidos ao professor foram simplificados aos poucos ao longo dos anos. Reverter isso é preocupação política dos professores, que precisam se organizar coletivamente. Trata-se de fazer não apenas uma opção política no discurso, pois, se assim for, a ela dispensa o saber. Além da opção política, é necessário compromisso político, vinculado ao domínio dos conteúdos que se almejam transmitir, seus fundamentos e princípios.

Um segundo desafio educativo, na formação profissional, é a constituição de um novo gestor. Os educadores, de um modo geral, nas suas atividades pedagógicas corriqueiras, exercitam o papel de gestores. Alguns exercem esse papel de modo bem específico, na medida em que são diretores, coordenadores de curso, presidentes ou coordenadores de comissões. O desafio, então, é no sentido de incorporar a democracia enquanto participação popular, seja protagonizada pela participação de membros das comunidades camponesas, seja protagonizada pela participação dos estudantes; pois 
[...] a juventude já não pede. Exige que se reconheça o direito de exteriorizar esse pensamento próprio nos corpos universitários por meio de seus representantes. Está cansada de suportar os tiranos. Se foi capaz de realizar uma revolução nas consciências, não pode desconhecer-se a capacidade de intervir no governo de sua própria casa (MANIFESTO..., 1918, p. 3-4).

Nesse cenário, o curso de licenciatura Educação do Campo apresenta-se na luta pela democratização dos espaços, amparado em princípios democráticos, de participação e cidadania, de modo a garantir a todos os segmentos da comunidade camponesa, bem como da comunidade acadêmica, ampla participação nas propostas e ações desenvolvidas pelo curso. Consideram-se o protagonismo dos estudantes e sua participação nos momentos e espaços universitários de gestão como aspecto primordial para sua formação, uma vez que isso viabiliza uma percepção diferente da realidade, quiçá mais reflexiva e crítica, além de significar inserção nos contextos social e cultural. Tal formação orientada pela participação na coletividade abre espaço para pensar o mundo e a sociedade de modo a superar a concepção mercadológica, capitalista, de democracia que visa apenas ao acesso e ao consumo no sentido econômico. Com isso, o estudante protagonista tem condições de compreender a totalidade da vida social em suas grandezas, contradições, incoerências e descontinuidades, com capacidade de questionar a consistência e a coerência de suas vivências.

A participação dos estudantes, sujeitos aprendizes, está além do tempo, do espaço e dos recursos disponíveis na sala de aula, isto é, perpassa outros espaços e momentos com potencial educativo, como a reflexão sobre as vivências na sua comunidade de origem, a valorização de sua cultura e a participação nas instâncias decisórias institucionais, especialmente por meio da organização do movimento estudantil e de agremiações. Não é exagero lembrar que as instituições escolares, universitárias, deveriam fomentar a convivência cooperativa.

É com convicção que identificamos liberdade com o poder de conceber projetos, de os traduzir em atos. Esta liberdade é, por sua vez, idêntica ao autocontrolo, porque a concepção dos fins e a organização dos meios são um trabalho da inteligência. Outrora, Platão definia o escravo por estas palavras: "Aquele que executa os projetos concebidos pelos outros", e, como acabamos de dizer, não é menos escravo a pessoa submetida aos seus próprios desejos, se eles forem cegos. Penso que não há, em toda a filosofia da educação progressiva, disposição mais judiciosa que esta importância dada à participação do educando na concepção de projetos que inspiram as suas atividades no decurso do ensino que lhes ministramos. E também não há, na educação tradicional, defeito mais grave que tornar o educando incapaz de cooperar ativamente na construção de projetos intelectuais que os seus estudos implicam (DEWEY, 1990, p. 15).

A convivência com visões de mundo e concepções de sociedade e projeto social diferentes tende a contribuir não somente para o aprendizado de um modo geral, 
mas também para ampliar a sua percepção e a consolidação de princípios intrínsecos aos ideais de organização social que se almeja e a valorização da cultura da sua comunidade, pois

O respeito a toda diversidade presente na cultura do jovem e da comunidade em que está inserido significa, antes de tudo, respeitá-lo como cidadão em seu direito à participação e à interferência na organização social, democratizando o espaço da escola para que as manifestações culturais locais estejam presentes, valorizando as pessoas e suas experiências e vivências (FRANCO, 2006, p. 67).

Ações nessa direção aproximam o estudante e a comunidade da universidade e valorizam-nos como coadjuvantes na construção de cultura e conhecimento, não apenas como meros receptores ou expectadores de um processo. No intuito de valorizar essa participação da comunidade, inclusive nos processos avaliativos, o curso de Educação do Campo propõe uma inovação na Unipampa, experiência pioneira: a constituição de um conselho comunitário (CC), a saber:

O CC é um órgão de assessoria e consultoria junto à Comissão e à Coordenação de Curso, acompanhando e sugerindo melhorias relativas às matérias de interesse coletivo e comunitário, quando assim for demandado. Este conselho será composto por um Representante Comunitário, das escolas de Ensino Fundamental e Médio de cada um dos municípios de domicílio dos acadêmicos regulares do Curso de Educação do Campo - Licenciatura da UNIPAMPA. O CC será presidido pelo Coordenador do Curso de Educação do Campo Licenciatura da UNIPAMPA e reunir-se-á, semestralmente, antes do início de cada Tempo Universidade (UNIVERSIDADE FEDERAL DO PAMPA, 2016, p. 41-42).

A parceria com a comunidade tende a gerar mútuos benefícios, no sentido de que tanto o conhecimento possa ser avalizado e ter seu critério de veracidade corroborado pela sociedade ou comunidade, quanto a inovação possa adentrar a universidade e retroalimentá-la, uma vez que se suprem as lacunas dessa relação. Embora tenha se conseguido criar o CC, internamente, encontraram-se barreiras burocráticas, por vezes de apego corporativo, para que se possa dar mais autonomia e poder decisório ao conselho. Contudo, é possível observar uma mudança na cultura universitária, ao menos local, uma vez que isso se tornou objeto de discussão, e nota-se a presença de representantes de diversos segmentos da sociedade organizada incorporados (atores sociais) nas reuniões periódicas. Do lado da comunidade, apesar dos "olhares tímidos", percebe-se mais engajamento, apesar da necessidade constante de mobilização, uma vez que esta relação (universidade e comunidade) ainda não ocorre com frequência ou, quando ocorrem, está atrelada ao sentido estritamente econômico de financiamento de projetos de pesquisa ou de formação de mão de obra qualificada (parceria público-privada, neste caso).

Enfim, busca-se com isso a formação de educadores que compreendam os fundamentos do processo de aprendizagem dos conteúdos das ciências da natureza, re- 
lacionando-os com os fenômenos naturais que compõem a realidade dos educandos do campo, e que consigam, desde a sua formação, ter a comunidade e a sociedade como balizadores e referencial do conhecimento, isto é, a formação de profissionais engajados socialmente.

\section{Elementos de conclusão}

A experiência desenvolvida no curso de licenciatura Educação do Campo colabora para repensar a atuação das instituições escolares, entre elas, as universidades. Busca-se com o curso uma formação acadêmica e profissional que extrapole os limites dos livros didáticos. A relação entre a teoria e a prática, por meio de um calendário acadêmico diferenciado, possibilita o vínculo dos professores e estudantes com a comunidade e, com isso, o vínculo do processo de aprendizado com a vida comunitária. Essa perspectiva tende a colaborar para a "efetivação do compromisso social da universidade em construir e socializar conhecimentos, atitudes e valores que tornem os indivíduos (cidadãos) mais éticos, solidários e participativos em uma perspectiva emancipatória" (ROCHA, 2008, p. 221).

Tal compromisso perpassa pela efetivação, necessariamente, do protagonismo dos estudantes, da juventude, dentro do espaço escolar, universitário, requisitado desde o Manifesto de Córdoba em 1918, e, muito mais, pela efetivação da relação universidade e comunidade, superando as barreiras históricas, especialmente o fato de as universidades centrarem seus esforços no ensino e na pesquisa, na produção de conhecimentos, denunciada corretamente em muitos casos por esses conhecimentos não valorizarem a cultura das comunidades, em especial, das comunidades camponesas, ou, então, estarem alijados da vida social concreta.

Nesse sentido, a atuação dos educadores deve ser diferente, pois é necessária uma visão mais ampliada da realidade. É necessário o reconhecimento de que o processo de ensino e aprendizado deve levar em consideração os contextos nos quais educadores e educandos estão inseridos, objetivando com isso a formação condizente com um mundo real, que faz sentido para ambos. Nesse aspecto, a articulação dos conhecimentos a partir de eixos articuladores e temáticos possibilita e, ao mesmo tempo, exige a prática da interdisciplinaridade, em que o conhecimento individual passa a ser um fator colaborativo, e não determinante.

Também se desafia com essa proposta de graduação a estrutura institucional da universidade, pois é necessário o entendimento de que o processo de ensino e aprendizado não ocorre apenas em sala de aula, sendo imprescindível a imersão na comunidade, na realidade social. Para isso, exigem-se uma estrutura física diferenciada, um sistema de registro acadêmico adaptado e a disponibilidade de pro- 
fissional para sair de um espaço de conforto e conhecer e desenvolver os conteúdos programáticos fora dos muros da universidade.

A formação de novos(as) educadores(as) e estudantes exige que, ao contrário do enfoque reducionista e cartesiano da formação profissional convencional, se adote uma formação mais multidisciplinar ou, pelo menos, se ampliem aspectos formativos que levem a uma maior capacidade de dialogar com realidades fora da sala de aula.

Ainda, o regime de alternância, a Pedagogia de Alternância, nos aspectos adotados, permite o vínculo dos estudantes com suas comunidades, com seus locais de produção de vida, de modo que esse envolvimento contribui para organizar coletivamente as famílias e/ou os grupos sociais, as comunidades, trazendo como possibilidades claras a implantação de iniciativas e/ou projetos de desenvolvimento comunitário sustentável, um projeto popular de sociedade pautado na superação das relações de produção, construídas com base na propriedade privada, bem como a transformação social pelo veio democrático, de formação humanista, valorizando as peculiaridades de cada comunidade.

Subverte-se com essa perspectiva, enquanto proposta, a separação campo-cidade que está no bojo da organização das relações de produção da sociedade capitalista. A percepção mais apurada da unidade teoria-prática recupera o papel de sujeitos, traz possibilidades de emancipação para esses camponeses - povos que tradicionalmente tiveram um papel subordinado e de assujeitamento em relação ao modo capitalista de produção, colocado como único possível e viável -, especialmente, porque mostra que há alternativas viáveis de produção da vida.

A formação dos profissionais da educação tem um grande potencial de transformação social, mas o próprio processo formativo precisa viabilizar a formação no sentido amplo, da formação humana omnilateral, emancipatória e crítica, que só ocorre na medida em que a própria universidade e os cursos se reformam e lançam mão de alternativas que superam a corriqueira formação baseada no ensino e na pesquisa.

Se não existe uma vinculação espiritual entre o que ensina e o que aprende, todo ensino é hostil e, por conseguinte, infecundo. Toda a educação é uma longa obra de amor aos que aprendem. Fundar a garantia de uma paz fecunda no artigo combinatório de um regulamento ou de um estatuto é, em todo caso, amparar um regime de quartel, mas não um trabalho de ciência (MANIFESTO..., 1918, p. 1).

Essa concepção de educação, ensino de ciências e formação de professores parece ser o norte do curso Educação do Campo e, sem dúvida, a orientação mais profícua. 


\section{Referências}

CHAUÍ, Marilena. Cidadania Cultural: o direito à cultura. São Paulo: Fundação Perseu Abramo, 2006.

DEWEY, Jonh. Trabalho de projeto. Porto: Afrontamento, 1990.

DUARTE, Newton. Críticas ao fetichismo da individualidade. Campinas: Autores Associados, 2004.

FÓRUM DE PRÓ-REITORES DE EXTENSÃO DAS UNIVERSIDADES PÚBLICAS BRASILEIRAS. Plano Nacional de Extensão Universitária. Ilhéus: Editus, 2001.

FRANCO, Francisco Carlos. O protagonismo juvenil e a coordenação pedagógica. In: ALMEIDA, Laurinda Ramalho; PLACCO, Vera Maria Nigro de Souza. O coordenador pedagógico e as questões da contemporaneidade. São Paulo: Loyola, 2006. p. 61-80.

FREIRE, Paulo. Extensão ou comunicação? 14. ed. Rio de Janeiro: Paz e Terra, 2010.

MANIFESTO de Córdoba. 1918. Disponível em: <https://ufscaesquerda.com.br/wp-content/uploads/2015/06/Manifesto-de-C\%C3\%B3rdoba-1918-Portugu\%C3\%AAs-e-Espanhol.pdf $>$. Acesso em: 15 jun. 2018.

MARIÁTEGUI, José Carlos. 7 Ensayos de Interpretación de la Realidad Peruana. 44. ed. Lima: Empresa Editora Amauta, 1981.

NOGUEIRA, Maria das Dores Pimentel. Políticas da extensão universitária brasileira. Belo Horizonte: Ed. UFMG, 2005.

NOSELLA, Paolo. Educação no campo: origens da pedagogia da alternância no Brasil. Vitória: Edufes, 2012.

UNIVERSIDADE FEDERAL DO PAMPA. Plano de Desenvolvimento Institucional 2014 -2018. Bagé: Unipampa, 2013.

. Projeto Político Pedagógico do Curso de Educação do Campo - Licenciatura. Dom Pedrito: Unipampa, 2016.

ROCHA, José Cláudio. A reinvenção solidária e participativa da universidade: um estudo sobre redes de extensão universitária no Brasil. Salvador: Eduneb, 2008.

SAVIANI, Dermeval. Interlocuções pedagógicas: conversa com Paulo Freire a Adriano Nogueira. Campinas: Autores Associados, 2010. 